\title{
Utilização de Enzimas Exógenas em Dietas com Diferentes Fontes e Níveis de Proteína para Leitões na Fase de Creche ${ }^{1}$
}

\section{Alexandre de Oliveira Teixeira ${ }^{2}$, Darci Clementino Lopes ${ }^{3}$, Vanusa Patrícia de Araújo Ferreira ${ }^{4}$, Sérgio Miranda Pena ${ }^{5}$, Eduardo Terra Nogueira 6 , José Aparecido Moreira ${ }^{7}$, Silvano Bünzen ${ }^{5}$, Lidson Ramos Nery 5}

\begin{abstract}
RESUMO - Dois experimentos foram conduzidos para avaliar a inclusão de enzimas exógenas em dietas com diferentes níveis e fontes de proteína para leitões. No experimento I, 80 leitões dos 21 aos 51 dias de idade, desmamados aos 14 dias de idade, foram distribuídos em blocos casualizados, em esquema fatorial 2x2x2 (dois níveis de proteína; com ou sem farinha de carne e ossos; com ou sem enzima), com cinco repetições e dois leitões/baia, e alimentados com dietas à base de milho (M), farelo de soja (FS) e soro de leite em pó (SLP). No experimento II, 40 leitões dos 28 aos 45 dias de idade, desmamados aos 21 dias de idade, foram distribuídos em blocos casualizados, com quatro tratamentos, cinco repetições e dois animais/baia, e alimentados com uma dieta controle à base de M, FS e SLP, com $18 \%$ de proteína bruta $(\mathrm{PB})$ e três rações com 0,$2 ; 0,4$ e $0,6 \%$ do complexo enzimático. No experimento I, não foi observada interação entre nível protéico, com ou sem farinha de carne e ossos e enzima. Houve diminuição do GPD e CMD, com o nível de $18 \%$ de PB na ração. Não houve efeito da inclusão de FCO e de 0,2\% de enzima na ração. No experimento II, houve efeito linear crescente para GPD e CMD, com o aumento do nível de enzimas. A adição de $0,4 \%$ de enzimas exógenas proporcionou o melhor retorno econômico sobre o custo da ração. Concluiu-se que o nível de $21 \%$ de PB e a adição de níveis crescentes de enzimas exógenas em rações à base de milho e farelo de soja melhoram o desempenho dos leitões, que não é afetado pela inclusão de 5\% de farinha de carne e ossos na ração.
\end{abstract}

Palavras-chave: amilase, celulase, desmame, farinha de carne e ossos, protease, suínos

\section{Exogenous Enzymes in Diets with Different Protein Levels and Sources for Pigs in the Nursery Period}

\begin{abstract}
Two experiments were carried out to evaluate the inclusion of exogenous enzymes in diets with different protein levels and sources for pigs during the nursery period. In the first experiment, 80 pigs from 21 to 51 days of age, weaned at 14 days of age, were assigned to a randomized blocks experimental design, in a $2 \times 2 \times 2$ factorial (two protein levels; with or without meat and bone meal; with or without enzyme), with five replicates and two pigs/box, and fed a corn (C), soybean meal (SBM) and dried whey (DW)-based diets. In the second experiment, 40 pigs from 28 to 45 days of age, weaned at 21 days of age, were assigned to a randomized blocks, with four treatments, five replicates and two pigs/box, fed a control diet (C, SBM and DW-based diet with $18 \%$ crude protein - CP) and three diets with different levels of enzymatic complex $(0.2,0.4$ and $0.6 \%)$. In the first experiment, no interaction was observed among protein level, presence or absence of meat and bone meal (MBM) and presence or absence of enzyme. Reduction of ADG and ADFI was observed at the dietary level of $18 \% \mathrm{CP}$. No effect of MBM inclusion and $0.2 \%$ enzyme in the diet was detected. In the experiment II, it was observed increasing linear effect for ADG and ADFI, as the enzyme level increase. The addition of $0.4 \%$ of exogenous enzymes provided the best economical return for the ration cost. It was concluded that the level of $21 \% \mathrm{CP}$ and the addition of increasing exogenous enzyme levels in corn and soybean meal-based diets improve pig performance, that is not affected by the inclusion of $5 \%$ the meat and bone meal in the diets.
\end{abstract}

Key Words: amylase, cellulase, meat and bone meal, protease, swine

\section{Introdução}

A alimentação dos suínos, principalmente na fase pós-desmame, requer atenção especial dos pesquisadores, uma vez que, nesta fase, existe a necessidade do fornecimento de uma ração que substitua o leite da mãe, fornecendo, a baixo custo, quantidade significativa de nutrientes em proporções adequadas para reduzir o estresse e aumentar a taxa de crescimento, diminuindo a mobilização de reservas de

\footnotetext{
${ }^{1}$ Projeto parcialmente financiado pela Alltech do Brasil.

2 Zootecnista e doutor em Zootecnia - Assistente Técnico - Bunge Fertilizantes (alexandre.teixeira@bunge.com).

3 Professor do Departamento de Zootecnia - UFV - 36.571-000 - Viçosa - MG.

4 Zootecnista e professora titular da FEAD - Belo Horizonte - MG.

5 Zootecnista, mestrando em Zootecnia - UFV - 36571-000 - Viçosa - MG.

${ }^{6}$ Médico Veterinário, Doutor em Zootecnia - UFV - 36571-000 - Viçosa - MG.

7 Pesquisador CENA/USP - Piracicaba - SP.
} 
lipídeos. Logo, torna-se necessária a avaliação do nível e da fonte de proteína para substituição de produtos à base de leite, que são caros e nem sempre disponíveis (Trindade Neto et al., 1994).

A utilização de enzimas exógenas (amilase, protease, lipase, xilanase, fitase etc) surgiu como uma alternativa para aumentar o valor nutritivo de ingredientes alimentares que possuem baixos coeficientes de digestibilidade e apresentam significativa fração de polissacarídeos não-amiláceos estruturais e/ou fatores antinutricionais, que não são hidrolisados pelas enzimas digestivas dos suínos (Furlan et al., 1997), diminuindo, assim, a viscosidade da dieta (Graham, 1996).

O fornecimento de enzimas exógenas em forma de coquetel também é feita em rações de leitões em situações que debilitam a produção de enzimas endógenas, como estresse do desmame, vacinação, castração e desconforto térmico (Ferket, 1996). Geralmente, o coquetel é formado por protease, amilase e lipase, pois os níveis destas enzimas endógenas diminuem por várias semanas, causando problemas de digestão e resultando em redução na absorção e em diarréia (Wenk, 1993).

Soto (1996) afirma que estas enzimas já estão no mercado, com resultados iniciais promissores, e que sua adição em rações pode se tornar prática rotineira e com boa relação custo/benefício, como é o caso de dietas à base de trigo e cevada.

A utilização de enzimas em dietas de baixa viscosidade (milho, sorgo e farelo de soja) e outros ingredientes produzidos no Brasil possui intuito mais econômico que ambiental (Firemen et al., 1998).

É importante resaltar que nem sempre a suplementação com enzimas digestivas proporciona resposta positiva. Para as enzimas atuarem, são necessários substratos específicos na dieta, dosagem correta de enzimas, capacidade das enzimas para ultrapassar barreiras no estômago, como $\mathrm{pH}$ baixo, ação de enzimas proteolíticas, como a pepsina, e processamento a que o alimento é submetido (Penz Jr., 1998).

Para que se possa reduzir efetivamente o custo das rações com adição de complexo de enzimas exógenas, fatores como a relação entre as enzimas utilizadas e os substratos da ração, os aumentos da digestibilidade dos nutrientes e os aspectos de formulação das rações devem ser considerados (Hannas \& Pupa, 2003).
Easter et al. (1988) comprovaram que produtos enzimáticos contendo amilases e proteases em dietas à base de milho e farelo de soja durante as três primeiras semanas após a desmama aumentam a capacidade digestiva do animal, a digestibilidade de matéria seca e nitrogênio. Entretanto, Nery et al. (1997a,b) e Nery et al. (2000) não encontraram variação no desempenho de leitões, ao fornecerem o complexo enzimático na proporção recomendada pela indústria.

Este trabalho foi conduzido com o objetivo de se avaliar a utilização do complexo enzimático exógeno em rações com dois níveis de proteína; com ou sem farinha de carne e ossos para leitões na fase de 21 a 51 dias de idade.

\section{Material e Métodos}

Foram realizados dois experimentos no setor de Suinocultura do Departamento de Zootecnia da Universidade Federal de Viçosa (UFV), em ViçosaMG, Brasil, no período de junho a novembro de 1999.

Os experimentos foram realizados em salas de creche construídas em alvenaria, com piso de concreto, forro de madeira, janelas de vidro tipo basculante, contendo gaiolas metálicas suspensas, medindo 1,60 x 1,0 x 0,56m, providas de piso em plástico expandido, laterais em tela metálica, lâmpadas de aquecimento, comedouros semi-automático e bebedouros tipo chupeta, onde as dietas e a água foram fornecidas à vontade.

As dietas experimentais foram formuladas para atender às exigências nutricionais dos leitões na fase, conforme recomendações de Rostagno et al. (1992). A composição centesimal e os valores nutricionais das dietas experimentais são apresentados na Tabela 1.

No primeiro experimento, foram utilizados 80 leitões mestiços (Landrace x Large White x Duroc), machos castrados e fêmeas, desmamados aos 14 dias de idade e distribuídos nos tratamentos aos 21 dias de idade. $\mathrm{O}$ delineamento experimental foi em blocos casualizados, com oito tratamentos, em esquema fatorial 2x2×2 (dois níveis de proteína, inclusão ou não de farinha de carne e ossos; suplementação ou não com complexo enzimático composto por protease, amilase e celulase - Allzyme Vegpro ${ }^{\circledR}$, na proporção de $2 \mathrm{~kg} / \mathrm{ton}$, segundo recomendações do fabricante (Alltech do Brasil), cinco repetições e dois leitões (um macho e uma fêmea) por unidade experimental. 
Tabela 1 - Composição percentual das dietas experimentais

Table 1 - Percentage composition of the experimental diets

\begin{tabular}{|c|c|c|c|c|c|}
\hline \multirow{4}{*}{$\begin{array}{l}\text { Ingrediente (\%) } \\
\text { Ingredient }\end{array}$} & \multicolumn{5}{|c|}{ Dietas experimentais (Experimental diets) } \\
\hline & \multicolumn{4}{|c|}{$\begin{array}{l}\text { Experimento I } \\
\text { Experiment I }\end{array}$} & $\begin{array}{c}\text { Experimento II } \\
\text { Experiment II }\end{array}$ \\
\hline & \multicolumn{2}{|c|}{$\mathrm{C} / \mathrm{FCO}^{\mathrm{a}}$} & \multicolumn{2}{|c|}{$\mathrm{S} / \mathrm{FCO}^{\mathrm{b}}$} & \multirow[b]{2}{*}{ Controle } \\
\hline & $18 \% \mathrm{~PB}$ & $21 \% \mathrm{~PB}$ & $18 \% \mathrm{~PB}$ & $21 \% \mathrm{~PB}$ & \\
\hline Milho (Corn) & 53,00 & 43,46 & 50,89 & 41,71 & 58,52 \\
\hline Farelo de soja (Soybean meal) & 19,80 & 29,72 & 25,45 & 34,90 & 26,60 \\
\hline Farinha de carne e ossos & 5,44 & 5,16 & - & - & - \\
\hline $\begin{array}{l}\text { Meat and bone meal } \\
\text { Soro de leite em pó } \\
\text { Dried whey }\end{array}$ & 20,00 & 20,00 & 20,00 & 20,00 & 10,00 \\
\hline Óleo de soja (Soybean oil) & 0,716 & 1,020 & 0,534 & 0,760 & 0,851 \\
\hline Calcário (Limestone) & - & - & 0,932 & 0,900 & 0,982 \\
\hline Fosfato bicálcico & - & - & 1,188 & 1,090 & 1,453 \\
\hline Dicalcium phosphate & & & & & \\
\hline Sal (Salt) & 0,013 & 0,008 & 0,065 & 0,059 & 0,223 \\
\hline L- Lisina $\mathrm{HCl}$ & 0,365 & 0,057 & 0,299 & - & 0,357 \\
\hline L- Lysine $\mathrm{HCl}-78.4 \%$ & & & & & \\
\hline DL-Metionina & 0,126 & 0,035 & 0,102 & 0,041 & 0,110 \\
\hline $\begin{array}{l}\text { DL- Methionine - } 99 \% \\
\text { Cloreto de colina } \\
\text { Choline chlorate }\end{array}$ & 0,030 & 0,030 & 0,030 & 0,030 & 0,030 \\
\hline $\begin{array}{l}\text { Premix vitamínico } \\
\text { Vitamin premix }\end{array}$ & 0,100 & 0,100 & 0,100 & 0,100 & 0,100 \\
\hline Premix mineral $^{2}$ & 0,100 & 0,100 & 0,100 & 0,100 & 0,100 \\
\hline $\begin{array}{l}\text { Mineral premix } \\
\text { Caulim (Inert) }\end{array}$ & & & & & \\
\hline $\begin{array}{l}\text { Caulim (Inert) } \\
\text { Virginamicina-20 g }\end{array}$ & $0,200^{c}$ & $0,200^{\circ}$ & $0,200^{c}$ & $0,200^{\mathrm{c}}$ & $0,600^{\mathrm{d}}$ \\
\hline Virginamicina $-20 \mathrm{~g}$ & 0,100 & 0,100 & 0,100 & 0,100 & 0,100 \\
\hline $\begin{array}{l}\text { Virginamicin }-20 \mathrm{~g} \\
\text { Antioxidante } \mathrm{BHT} \\
\text { Antioxidant - } B H T \\
\end{array}$ & 0,010 & 0,010 & 0,010 & 0,010 & 0,010 \\
\hline Total & 100 & 100 & 100 & 100 & 100 \\
\hline Proteína bruta (\%) & 18 & 21 & 18 & 21 & 18 \\
\hline $\begin{array}{l}\text { Crude protein } \\
\text { Energia digestível }(\mathrm{kcal} / \mathrm{kg}) \\
\text { Digestible energy }\end{array}$ & 3390 & 3390 & 3390 & 3388 & 3390 \\
\hline Lactose $(\%)$ & 14,00 & 14,00 & 14,00 & 14,00 & 7,00 \\
\hline Cálcio (Calcium) (\%) & 0,905 & 0,905 & 0,905 & 0,902 & 0,905 \\
\hline Fósforo disponível (\%) & 0,551 & 0,544 & 0,464 & 0,454 & 0,446 \\
\hline Available phosphorus & & & & & \\
\hline Lisina (Lysine) $(\%)$ & 1,23 & 1,23 & 1,23 & 1,23 & 1,23 \\
\hline Metionina (\%)(Methionine) & 0,39 & 0,35 & 0,38 & 0,36 & 0,39 \\
\hline Triptofano (Tryptophan) (\%) & 0,22 & 0,27 & 0,24 & 0,28 & 0,23 \\
\hline
\end{tabular}

${ }^{1}$ Conteúdo/kg de premix (Content/kg of the premix): vit. A, $9.000 .000 \mathrm{UI}$; vit. $\mathrm{D}_{3}, 900.000 \mathrm{UI}$; vit. E, $10.000 \mathrm{UI}$; vit. $\mathrm{K}_{3}, 4 \mathrm{~g}$; vit. $\mathrm{B}_{1}$, 2 g; vit. $\mathrm{B}_{2}$, $5 \mathrm{~g}$; vit. $\mathrm{B}_{6}, 5 \mathrm{~g}$; vit. $\mathrm{B}_{12}, 40 \mathrm{mg}$; ácido nicotínico (nicotinic acid), $40 \mathrm{~g}$; ácido pantotênico (panthotenic acid), $25 \mathrm{mg}$; selenito de sódio (selenium sodium), $50 \mathrm{mg}$; e veículo q.s.p., $1.000 \mathrm{~g}$.

${ }^{2}$ Conteúdo/kg de premix (Content/kg of the premix): ferro (iron), $180 \mathrm{~g}$; cobre (copper), $20 \mathrm{~g}$; cobalto (cobalt), $4 \mathrm{~g}$; manganês (manganese), $80 \mathrm{~g}$; zinco (zinc), $140 \mathrm{~g}$; iodo (iodine), $4 \mathrm{~g}$; e veículo q.s.p., $1.000 \mathrm{~g}$

a Com farinha de carne e ossos (With meat and bone meal). b Sem farinha de carne e ossos (Without meat and bone meal).

c,d Sem ou com enzima na substituição do caulim (With or without enzyme in substitution of caulin).

As sobras de ração caídas dos cochos foram varridas e coletadas diariamente para determinação do consumo. Durante o período experimentoal (30 dias), os leitões foram pesados a cada 15 dias, calculando-se o consumo de ração e a conversão alimentar (CA).
No experimento II, foram utilizados 40 leitões mestiços (Landrace x Large White x Duroc), machos castrados e fêmeas, desmamados aos 21 dias de idade. $\mathrm{O}$ delineamento experimental foi em blocos casualizados, com quatro tratamentos, cinco repeti- 
ções e dois animais/baia (um macho e uma fêmea). Os tratamentos consistiram de uma dieta controle (Tabela 1), representando o nível zero de enzima e mais três dietas contendo 0,$2 ; 0,4$ e $0,6 \%$ do complexo enzimático Allzyme Vegpro ${ }^{\circledR}$.

Os leitões foram distribuídos nos tratamentos aos 28 dias de idade $(7,09 \pm 1,12 \mathrm{~kg})$ e pesados aos 45 dias de idade, quando também foram estimados o de ração e a conversão alimentar durante a fase experimental (17 dias).

A análise econômica foi feita utilizando-se o conceito de índice de rentabilidade (IR) ou rentabilidade simples (Buarque, 1991), que determina a taxa de retorno sobre os custos, isto é, demonstra o retorno líquido de cada unidade monetária gasta nas despesas incorridas na produção.

O IR foi determinado de acordo com a seguinte expressão:

$$
I R=\left(\sum_{i=1}^{n} Y i \times P-\sum_{i=1}^{n} C O N R i \times P R i\right) / \sum_{i=1}^{n} C O N R i \times P R i
$$

em que IR = índice de rentabilidade; Yi = peso do animal no tratamento $\mathrm{i} ; \mathrm{P}=$ preço por $\mathrm{kg}$ do animal; CONRi $=$ consumo de ração no tratamento $i$; e Pri $=$ preço da ração no tratamento $i$.

A determinação dos custos das rações foi realizada com base nos preços dos ingredientes em setembro de 2003 e os preços dos suínos, a partir do preço pago ao produtor na granja, no período de agosto a setembro de 2003.

As análises estatísticas das variáveis de desempenho foram realizadas pelo Sistema de Análises Estatísticas e Genética (SAEG), desenvolvido na UFV (1998). A comparação entre as médias foi feita pelo teste de Student Newman-Keuls, empregando-se regressão para observar o comportamento dos parâmetros, em função dos níveis enzimáticos no segundo experimento.

\section{Resultados e Discussão}

Os resultados de peso $(\mathrm{P})$, ganho de peso médio diário (GPD), consumo médio diário (CMD) e conversão alimentar (CA) dos animais, no experimento I, encontram-se na Tabela 2.

Não foi observada interação $(\mathrm{P}>0,05)$ entre os níveis com ou sem inclusão de farinha de carne e ossos nem com ou sem a utilização de enzimas.
Nenhuma diferença $(\mathrm{P}>0,05)$ com relação ao nível de proteína foi constatada no período de 21 a 36 e de 21 a 51 dias de idade para os parâmetros estudados. Entretanto, houve diferença $(\mathrm{P}<0,06)$ no período de 36 a 51 dias de idade, em que o tratamento com $21 \%$ de PB apresentou melhores resultados de GPD e maior CMD. Por outro lado, a inclusão de FCO a 5\% não afetou $(\mathrm{P}>0,05)$ o desempenho dos leitões.

Mead et al. (1969) utilizaram rações à base milho e soja para leitões e observaram que níveis de 12 e $15 \%$ de proteína bruta resultaram em pior desempenho dos 5,9 aos $23,5 \mathrm{~kg}$ que rações com níveis de proteína maiores. Campbell (1977) estudou níveis de proteína bruta (15 a 23\%) e observou que a taxa de deposição de proteína elevou, enquanto a de gordura diminuiu, com o aumento dos níveis de proteína.

Embora não tenham sido encontradas diferenças estatísticas significativas, animais que consumiram a ração à base de milho, farelo de soja e farinha de carne e ossos apresentaram redução numérica de $2,08 \%$ no GPD e de 3,29\% na CA no período de 21 a 51 dias de idade. Os resultados obtidos por Peo \& Hudman (1962), em três experimentos com suínos, somente demonstraram redução significativa na taxa de crescimento nos animais alimentados com rações contendo $10 \%$ de farinha de carne e ossos.

Também não houve diferença $(\mathrm{P}>0,05)$ entre o $\mathrm{P}$, GPD, CMD e CA dos leitões em todas as fases, para os tratamentos com ou sem a utilização de enzimas. Apesar disso, animais que consumiram a ração à base de milho e farelo de soja apresentaram melhora de 2,27\% no GPD e de 4,25\% na CMD, com a adição do complexo enzimático no período de 21 a 36 dias de idade, corroborando os dados observados por Nery et al. (2000), que não verificaram melhora significativa $(\mathrm{P}>0,05)$ no GPD de animais que consumiram dietas à base de milho e farelo de soja suplementadas com $0,075 \%$ de um complexo enzimático.

Resultados semelhantes foram obtidos por Soto (1996), em suínos com 7 a $23 \mathrm{~kg}$ de peso vivo, alimentados com rações à base de milho e farelo de soja adicionadas de um complexo enzimático comercial contendo amilase, protease e xilanase. Estes resultados são similares aos encontrados por Officer (1995), que adicionou $\beta$-glucanase, hemicelulase, pentosanase, amilase, proteinase e lipase na ração e não verificou influência sobre o consumo de ração, o ganho de peso e a conversão alimentar de leitões, durante as cinco semanas pós-desmama. Costa et al. 
Tabela 2 - Peso (P), ganho de peso (GPD), consumo médio (CMD) e conversão alimentar (CA) de leitões alimentados com rações contendo diferentes níveis de proteína, com ou sem a utilização de farinha de carne e ossos e com ou sem a utilização de enzimas exógenas

Table 2 - Weight (W), daily weight gain (DWG), daily feed intake (DFI) and feed/gain ratio(F/G) of pigs fed diets with different crude protein levels, with or without meat and bone meal and with or without exogenous enzymes

\begin{tabular}{|c|c|c|c|c|c|c|c|c|c|c|c|}
\hline \multirow{3}{*}{$\begin{array}{l}\text { Enzima (Enzyme) } \\
\text { Fonte (Source) } \\
\% \mathrm{~PB}(C P)\end{array}$} & \multicolumn{5}{|c|}{ Sem enzima (Withoutenzyme) } & \multicolumn{5}{|c|}{ Com enzima (Withenzyme) } & \multirow{3}{*}{$\begin{array}{l}\mathrm{CV} \\
\%\end{array}$} \\
\hline & \multicolumn{2}{|c|}{$\mathrm{C} / \mathrm{FCO}^{\mathrm{a}}$} & \multicolumn{2}{|c|}{$\mathrm{S} / \mathrm{FCO}^{\mathrm{b}}$} & \multirow{2}{*}{$\begin{array}{l}\text { Média } \\
\text { Mean }\end{array}$} & \multicolumn{2}{|c|}{$\mathrm{C} / \mathrm{FCO}^{\mathrm{a}}$} & \multicolumn{2}{|c|}{$\mathrm{S} / \mathrm{FCO}^{\mathrm{b}}$} & \multirow{2}{*}{$\begin{array}{l}\text { Média } \\
\text { Mean }\end{array}$} & \\
\hline & $18 \%$ & $21 \%$ & $18 \%$ & $21 \%$ & & $18 \%$ & $21 \%$ & $18 \%$ & $21 \%$ & & \\
\hline $\begin{array}{l}\text { Peso aos } 21 \text { dias }(\mathrm{kg}) \\
\text { Weight at } 2 \text { l davs }(\mathrm{kg})\end{array}$ & 5,36 & 5,19 & 5,23 & 5,38 & 5,29 & 5,30 & 5,38 & 5,22 & 5,23 & 5,28 & 4,94 \\
\hline $\begin{array}{l}\text { Peso aos } 36 \text { dias }(\mathrm{kg}) \\
\text { Weight at } 36 \text { days }(\mathrm{kg})\end{array}$ & 9,72 & 10,14 & 9,44 & 9,93 & 9,80 & 9,72 & 9,70 & 9,95 & 10,28 & 9,91 & 8,77 \\
\hline $\begin{array}{l}\text { Peso aos } 51 \text { dias }(\mathrm{kg}) \\
\text { Weight at } 51 \text { days }(\mathrm{kg})\end{array}$ & 18,22 & 18,84 & 17,97 & 18,84 & 18,47 & 17,77 & 18,37 & 18,13 & 19,32 & 18,40 & 8,13 \\
\hline $\begin{array}{l}\text { GPD de } 21 \text { aos } 36 \text { dias }(\mathrm{g}) \\
D W G \text { from } 21 \text { to } 36 \text { days }(g)\end{array}$ & 290 & 331 & 280 & 303 & 301 & 294 & 288 & 313 & 337 & 308 & 17,6 \\
\hline $\begin{array}{l}\text { CMD de } 21 \text { aos } 36 \text { dias }(\mathrm{g}) \\
\text { DFI from } 21 \text { to } 36 \text { days }(\mathrm{g})\end{array}$ & 422 & 411 & 376 & 413 & 405 & 416 & 403 & 416 & 460 & 423 & 15,54 \\
\hline $\begin{array}{l}\text { CA de } 21 \text { aos } 36 \text { dias }(\mathrm{g}) \\
\text { F/G from } 21 \text { to } 36 \text { days }(\mathrm{g})\end{array}$ & 1,47 & 1,25 & 1,34 & 1,35 & 1,35 & 1,42 & 1,45 & 1,31 & 1,37 & 1,39 & 10,16 \\
\hline $\begin{array}{l}\text { GPD de } 36 \text { aos } 51 \text { dias }(\mathrm{g}) \\
D W G \text { from } 36 \text { to } 51 \text { days }(\mathrm{g})\end{array}$ & $566 \mathrm{~b}$ & $583 \mathrm{a}$ & $568 b$ & $593 \mathrm{a}$ & 577 & $532 b$ & $577 \mathrm{a}$ & $545 b$ & $600 \mathrm{a}$ & 563 & 10,49 \\
\hline $\begin{array}{l}\text { CMD de } 36 \text { aos } 51 \text { dias }(\mathrm{g}) \\
\text { DFI from } 36 \text { to } 51 \text { days }(\mathrm{g})\end{array}$ & $876 b$ & $895 \mathrm{a}$ & $879 b$ & $889 a$ & 885 & $877 \mathrm{~b}$ & $921 \mathrm{a}$ & $828 \mathrm{~b}$ & 951a & 894 & 9,59 \\
\hline $\begin{array}{l}\text { CA de } 36 \text { aos } 51 \text { dias }(\mathrm{g}) \\
F / G \text { from } 36 \text { to } 51 \text { days }(\mathrm{g})\end{array}$ & 1,56 & 1,55 & 1,54 & 1,50 & 1,54 & 1,65 & 1,60 & 1,55 & 1,59 & 1,60 & 6,57 \\
\hline $\begin{array}{l}\text { GPD de } 21 \text { aos } 51 \text { dias }(\mathrm{g}) \\
D W G \text { from } 21 \text { to } 51 \text { days }(\mathrm{g})\end{array}$ & 428 & 455 & 424 & 448 & 433 & 415 & 430 & 430 & 469 & 436 & 10,69 \\
\hline $\begin{array}{l}\text { CMD de } 21 \text { aos } 51 \text { dias }(\mathrm{g}) \\
\text { DFD from } 21 \text { to } 51 \text { days }(\mathrm{g})\end{array}$ & 649 & 653 & 627 & 654 & 645 & 647 & 662 & 627 & 705 & 660 & 9,75 \\
\hline $\begin{array}{l}\text { CA de } 21 \text { aos } 51 \text { dias }(\mathrm{g}) \\
F / G \text { from } 21 \text { to } 51 \text { days }(\mathrm{g})\end{array}$ & 1,53 & 1,45 & 1,48 & 1,46 & 1,48 & 1,56 & 1,53 & 1,47 & 1,47 & 1,51 & 6,57 \\
\hline
\end{tabular}

a Com farinha de carne e ossos (With meat and bone meal); b Sem farinha de carne e ossos (Without meat and bone meal).

Médias, na mesma linha, seguidas de letras diferentes diferem pelo teste Newman-Keuls $(\mathrm{P}<0,06)$ (Means, within a row, followed different letters are different $[P<.05]$ by Newman-Keuls test).

(1979), utilizando complexo enzimático com amilase, protease e celulase em rações à base de milho, farelo de soja, farelo de trigo e farinha de carne, verificaram que a adição de níveis de 0,01 e 0,02\% do complexo enzimático não proporcionou diferença significativa no ganho de peso e na conversão alimentar nas fases de crescimento e terminação.

Pesquisas envolvendo a utilização de complexos enzimáticos em rações têm comprovado melhora significativa na conversão alimentar de suínos nas diferentes fases de produção e, em algumas situações, verificou-se aumento do ganho de peso dos animais, como nos trabalhos de Lindeman et al. (1997); Inborr \& Ogle (1988) e Collier \& Hard (1986). Em outros trabalhos, a adição de enzimas em rações com amilase, protease e polissacaridase para leitões recém-desmamados reduziu a incidência de diarréia nos animais (Inborr \& Ogle, 1988; Chesson, 1993). A suplementação de amilase em rações para leitões melhorou a digestibilidade de amido contido nos cereais (Officer, 1995; Acamovic \& McCleary, 1966), enquanto a adição de protease melhorou a digestibilidade de proteína (Corring et al., 1978).

Os resultados indicam que a suplementação das enzimas na forma de complexo não tem efeitos significativos sobre o GPD e CMD dos suínos, o que provavelmente se deve ao fato de o tipo e/ou a concentração das enzimas utilizadas nos tratamentos terem sido inadequados para confirmar as respostas esperadas.

Os resultados de P, GPD, CMD e de CA dos animais do experimento II encontram-se na Tabela 3.

A elevação dos níveis de inclusão de enzimas exógenas na ração proporcionou aumento linear no GPD $\left(\mathrm{P}<0,01 ; \hat{\mathrm{Y}}=0,29504+0,47152 \mathrm{X} ; \mathrm{R}^{2}=91 \%\right) \mathrm{e}$ no $\mathrm{CMD}\left(\mathrm{P}<0,01 ; \hat{\mathrm{Y}}=0,472602+0,43765 \mathrm{X} ; \mathrm{R}^{2}=77 \%\right)$. Entretanto, não houve diferença $(\mathrm{P}>0,05)$ para $\mathrm{CA}$ em função dos tratamentos. 
Tabela 3 - Médias de peso, ganho de peso diário, consumo diário e conversão alimentar de leitões alimentados com rações contendo níveis crescentes de enzimas exógenas

Table 3 - Average weight, daily weight gain, daily feed intake and feed/gain ratio of pigs fed diets with increasing enzymes exogenous levels

\begin{tabular}{|c|c|c|c|c|c|}
\hline \multirow[t]{2}{*}{$\begin{array}{l}\text { Parâmetro } \\
\text { Parameter }\end{array}$} & \multicolumn{4}{|c|}{$\begin{array}{l}\text { Ração experimental }^{1} \\
\text { Experimental diet }\end{array}$} & \multirow[t]{2}{*}{$\mathrm{CV}(\%)$} \\
\hline & 0 & 0,2 & 0,4 & 0,6 & \\
\hline $\begin{array}{l}\text { Peso inicial }(\mathrm{kg}) \\
\text { Initial weight }(\mathrm{kg})\end{array}$ & 7,03 & 7,18 & 7,00 & 7,17 & 4,03 \\
\hline $\begin{array}{l}\text { Peso final }(\mathrm{kg}) \\
\text { Final weight }(\mathrm{kg})\end{array}$ & $12,19 \mathrm{~b}$ & $12,36 a b$ & $12,80 \mathrm{ab}$ & $13,43 a$ & 5,2 \\
\hline $\begin{array}{l}\text { Ganho de peso diário (g/dia) } \\
\text { Daily weight gain (g/day) }\end{array}$ & $304 b$ & $305 \mathrm{ab}$ & $341 \mathrm{ab}$ & $368 \mathrm{a}$ & 11,12 \\
\hline $\begin{array}{l}\text { Consumo médio diário }(\mathrm{g} / \mathrm{dia})^{2} \\
\text { Daily feed intake }(\mathrm{g} / \text { day })\end{array}$ & $491 \mathrm{~b}$ & $489 b$ & $514 \mathrm{~b}$ & $591 \mathrm{a}$ & 10,24 \\
\hline $\begin{array}{l}\text { Conversão alimentar } \\
\text { Feed:gain ratio }\end{array}$ & 1,62 & 1,60 & 1,52 & 1,60 & 5,69 \\
\hline
\end{tabular}

${ }^{1}(\mathrm{P}<0,05)$ Médias seguidas de letras distintas na linha diferem entre si pelo teste Newman-Keuls.

$1(P<.05)$ Means followed by different letters within a line are different by Newman-Keuls test.

2 Efeito linear $(\mathrm{P}<0,01)$ (Linear effect $[P<.01])$.

Pelo teste de Newman-Keuls, observou-se diferença $(\mathrm{P}<0,05)$ somente no peso final, GPD e CMD entre o tratamento controle e a dieta contendo $0,6 \%$ de enzima.

Constatou-se que o nível de $0,2 \%$ recomendado pela indústria não foi diferente do tratamento sem enzima pelo teste de Newman-Keuls, de modo semelhante ao primeiro experimento, o que está de acordo com os resultrados observados por Nery et al. (2000), que não encontraram diferença para GPD e CMD entre a ração testemunha e a ração contendo $0,2 \%$ do complexo enzimático. Os resultados indicam que a suplementação do complexo enzimático no nível recomendado pela indústria não tem efeito sobre os parâmetros estudados, provavelmente em razão do nível de suplementação das enzimas ter sido insuficiente para confirmar as respostas esperadas e também pelo fato de a maioria das pesquisas ter sido realizada com rações à base de alimentos com altas concentrações de polisacarídeos não-amiláceos (Furlan, 1997), o que justificaria a obtenção de resultados significativos com nível de inclusão do complexo enzimático inferior a $0,2 \%$. Entretanto, em dietas à base de milho e farelo de soja, este nível de suplementação parece não ser adequado.

Os resultados da análise econômica (índice de rentabilidade) dos tratamentos são apresentados na Tabela 4. É importante salientar que o índice de rentabilidade adotado indica somente o retorno sobre os gastos associados à formulação da ração. Os demais componentes do custo de produção não foram incluídos na análise, o que não interfere na comparação entre as rações, uma vez que idênticos para todas as fases. Também foi considerado o preço $(1,65 \mathrm{R} \$ / \mathrm{kg})$ do suíno adulto, não considerando o preço dos animais após a fase de creche.

O estudo da análise econômica indicou que os animais que consumiram a ração com $0,4 \%$ de enzima exógena apresentaram o melhor índice de rentabilidade, de modo que, para cada $\mathrm{R} \$ 1,00$ gasto na compra dessa ração, obteve-se receita líquida de $\mathrm{R} \$ 0,586$, desconsiderando os demais custos de produção. $\mathrm{O}$ retorno sobre o custo da ração obtido com esse tratamento $(0,4 \%$ de enzimas exógenas) foi de, aproximadamente, 11; 9; e 10 centavos de real, respectivamente, superior ao retorno observado para os níveis de $0 ; 0,2$; e $0,6 \%$ de enzimas exógenas.

Tabela 4 - Índice de rentabilidade de cada ração experimental, em razão dos níveis crescentes de enzimas exógenas

Table 4 - Profitability index of each experimental diet, according to the increasing exogenous enzymes levels

\begin{tabular}{ccc}
\hline Nível & Custo & Índice \\
de enzimas $(\%)$ & da ração $(\mathrm{R} \$ / \mathrm{kg})$ & $\begin{array}{c}\text { Ie rentabilidade } \\
\text { Revel of }\end{array}$ \\
$\begin{array}{c}\text { Ration } \\
\text { enzymes }(\%)\end{array}$ & $\begin{array}{c}\text { Profitability } \\
\text { index }\end{array}$ \\
\hline 0 & 0,69 & 0,481 \\
0,2 & 0,72 & 0,492 \\
0,4 & 0,75 & 0,586 \\
0,6 & 0,78 & 0,489 \\
\hline
\end{tabular}




\section{Conclusões}

O nível de $21 \%$ de proteína bruta e a adição de níveis crescentes de enzimas exógenas em rações à base de milho e farelo de soja para suínos na fase de creche melhoram o desempenho, que não é afetado pela inclusão de 5\% de farinha de carne e ossos na ração.

\section{Literatura Citada}

ACAMOVIC, T.; McCLEARY, B.V. Optinizing the response. Feed Mix, v.4, n.4, p.14-17, 1996.

BUARQUE, C. Avaliação econômica de projetos: uma apresentação didática. Rio de Janeiro: Campus, 8.ed. 1991. 266p.

CAMBELL, R.G. The response of early-weaned pigs to various protein levels in a hih energy diet. Animal Production, v.24, n.1, p.69-75, 1977.

CHESSON, A. Feed enzymes. Animal Feed Science Technology, v.45, n.1, p.65-79,1993.

COLLIER, B.; HARDY, B. The use of enzymes in pig and poultry feeds. Part 2. Results of animal trials. Feed Compouder, v.6, n.2, p.28-30, 1986.

CORRING, T.; AUMAITRE, A.; DURAND, G. Development of digestive enzymes in the piglet from birth to 8 weeks. I. Pancreas and pancreatic enzymes. Nutrition Metabolism, v.22, n.1, p.231-243, 1978.

COSTA, V.; LOPES, J.; NICOLAIEWSKY, S. Efeito da suplementação enzimática em rações para suínos em crescimento e terminação. Revista Brasileira de Zootecnia, v.8, n.3, p.459-472, 1979 .

EASTER, R.A. Acidification of diets for pig. In: RECENT ADVACE IN ANIMAL NUTRITION, London, 1988. Anais... London: Haresing and Cole, 1988. p.61-71.

FERKET, P. Enzymes offer way to reduce waste, improve performance. Feedstuffs, v.1, p.30-34, 1996.

FIREMAN, F.A.T.; FIREMAN, A.K.B.A.T. Enzimas na alimentação de suínos. Ciência Rural, v.28, n.1, p.173-178, 1998.

FURLAN, A.C.; FRAIHA, M.; MURAKAMI, E. et al. Utilização de complexo enzimático em dietas de frangos de corte com triticale. 1. Ensaio de digestibilidade. Revista Brasileira de Zootecnia, v.26, n.4, p.759-764,1997.

GRAHAM, H. Mode de action of feed enzymes in dietas based on low viscous and viscous grains. In: SIMPÓSIO LATINO-AMERICANO DE NUTRIÇÃO DE SUÍNOS E AVES, 1996, Campinas. Anais... Campinas: Colégio Brasileiro de Nutrição Animal, 1996. p.60-69.

HANNAS, M.I.; PUPA, J.M.R. Enzimas: uma alternativa viável para enfrentar a crise na suinocultura. Revista PorkWorld, Ano 2, n.13, p.48-51, 2003.

INBORR, J.; OGLE, R.B. Effect of enzymes treatment of piglets feed on performance and post-weaning diarrhea. Swedish Journal Agricultural Research, v.18, n.2, p.129-133, 1988.

LINDEMANN, M.D.; GENTRY, J.L.; MONEGUE, H.J. et al. Determination of the contribution of the enzyme combination to the growth performance of pig. Journal of Animal Science, v.75, (Suppl. 1), p.184, 1997.
MEADE, R.J.; VERDMEDAHL, L.D.; RUST, J.W. et al. Effects of protein content of the diet the young pig on rate and efficiency of gain during early development and subsequent to $23,5 \mathrm{~kg}$, and carcass characteristics and composition of lean tissue. Journal of Animal Science, v.29, n.4, p.463$477,1969$.

NERY, V.L.H.; LIMA, J.A.F.; FIALHO, E.T. Efeito da adição de enzimas na ração sobre a digestibilidade em leitões. In: REUNIÃO ANUAL DA SOCIEDADE BRASILEIRA DE ZOOTECNIA, 34., 1997, Juiz de Fora. Anais... Juiz de Fora, Sociedade Brasileira de Zootecnia, 1997a. p.88-89.

NERY, V.L.H.; LIMA, J.A.F.; FIALHO, E.T. Efeito da adição de enzimas na ração sobre o desempenho de leitões em recria. In: REUNIÃO ANUAL DA SOCIEDADE BRASILEIRA DE ZOOTECNIA, 34., 1997, Juiz de Fora. Anais... Juiz de Fora, Sociedade Brasileira de Zootecnia, 1997b. p.143-145.

NERY, V.L.H.; LIMA, J.A.F.; NELO, R.C.A. Adição de enzimas exógenas para leitões dos 10 aos $30 \mathrm{~kg}$ de peso. Revista Brasileira de Zootecnia, v.29, n.3, p.794-802,2000.

OFFICER, D.I. Effect of multi-enzyme supplements on the growth performance of piglets during the pre and postweaning periods. Animal Feed Science Technology, v.56, p.55-65, 1995.

PENZ JR., A.M. Enzimas em rações para aves e suínos. In: REUNIÃO ANUAL DA SOCIEDADE BRASILEIRA DE ZOOTECNIA, 35., 1998, Botucatu. Anais... Botucatu: Sociedade Brasileira de Zootecnia, 1998. p.165-178.

PEO, E.R.; HUDMAN, D.B. Effect of levels of meat and bone scraps on growth rate and feed efficiency of growing-finishing swine. Journal of Animal Science, v. 21, p.787-790, 1962.

ROSTAGNO, H.S.; SILVA, D.J.; COSTA, P.M.A. et al. Composição de alimentos e exigências nutricionais de aves e suínos: tabelas brasileiras. Viçosa, MG: Universidade Federal de Viçosa,1992. 79p.

SOTO, S.M. The use of enzymes to improve the nutritional value of corn-soy diets for poultry and swine. In: SIMPOSIO LATINOAMERICANO DE NUTRIÇÃO DE SUÍNOS E AVES, 1996, Campinas. Anais... Campinas: Colégio Brasileiro de Nutrição Animal, 1996. p.1-13.

TRINDADE NETO, M.A.T.; LIMA, J.A.F.; BERTECHINI, A.G. et al. Dietas e níveis protéicos para leitões desmamados aos 28 dias de idade - fase inicial. Revista Brasileira de Zootecnia, v.23, n.1, p.92-99,1994.

UNIVERSIDADE FEDERAL DE VIÇOSA - UFV. Sistema para análises estatísticas e genéticas (SAEG). Viçosa, MG: UFV. Versão 8.1. 1999.

WENK, C. What are the benefits of carboydrase in the nutrition of monogastric farm animals. In: WENK, C.; BOESSINGER, M. (Eds.) Enzymes in animal nutrition. Kartause Ittingen, Switzerland: 1993.
Recebido em: 22/04/03 Aceito em: 14/04/05 